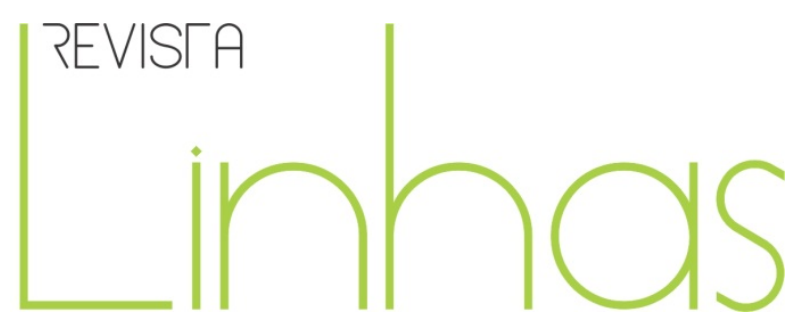

\title{
Cultura digital e gerações 2.0: para além dos neologismos e metáforas
}

PALFREY, John; GASSER, Urs. Nascidos na era digital: entendendo a primeira geração de nativos digitais. Porto Alegre: Artmed, 2011, 352 p.

\author{
Gilson Cruz Junior \\ Doutorando no Programa de Pós- \\ Graduação em Educação na \\ Universidade Federal de Santa Catarina \\ - PPGE/UFSC. \\ gijao05@hotmail.com
}

\section{Para citar esta resenha:}

JUNIOR, Gilson Cruz. Cultura digital e gerações 2.0: para além dos neologismos e metáforas. Revista Linhas, Florianópolis, v. 14, n. 27, jul./dez. 2013. p. $301-306$

\section{DOI: $10.5965 / 1984723814272013301$}

http://dx.doi.org/10.5965/1984723814272013301 
Lançado no ano de 2008, e publicado no Brasil em 2011 pela editora Artmed, sendo neste meio tempo traduzido para mais de dez línguas diferentes, o livro "Nascidos na era digital: entendendo a primeira geração de nativos digitais" (Born digital: understanding the first generation of digital natives) tem como objeto os jovens e crianças inseridos na paisagem tecnológico-comunicacional constituída a partir da ascensão e popularização das mídias digitais. Trata-se de uma iniciativa que se insere num contexto mais amplo de discussões, cujo principal mote se sustenta na premissa de que as novas tecnologias de comunicação e informação criaram um tipo particular de cisão geracional: de um lado, as crianças e jovens que cresceram no "mundo digital", e que por conta disso ostentam uma miríade de práticas, comportamentos e valores altamente sintonizados com o seu presente; de outro, seus pais e avós, membros das gerações anteriores, que aparentemente ainda "gaguejam" ao falar a língua das tecnologias (PRENSKY, 2001).

O livro em evidência é de autoria dos estadunidenses John Palfrey e Urs Gasser, ambos estudiosos da área do Direito, graduados pela Universidade de Harvard, instituição na qual atualmente exercem a função de docente, e também onde coordenam o Berkman Center for Internet \& Society. Suas principais investigações têm girado em torno de problemáticas inscritas na tríade composta por cultura digital, política e sociedade. Seus últimos estudos se direcionam a assuntos como: liberdade da e na internet; transparência e responsabilidade on-line; segurança e proteção infantil. É importante ressaltar ainda que diversas publicações de Palfrey e Gasser têm adquirido destaque no contexto dos EUA e de outros países do mundo, influenciando a proposição de ações estratégicas em vários setores, dentre os quais, encontra-se o das políticas educacionais - e seus respectivos processos de formulação e implementação.

Em linhas gerais, Nascidos na Era Digital consiste num extenso relato sociológico sobre o cotidiano das novas gerações, mais especificamente, dos nativos digitais, que busca entender os diferentes lugares assumidos por esse grupo no âmbito das mídias e de suas respectivas práticas. Todos estes são discutidos ao longo de 13 capítulos, cujos assuntos representam os principais papéis assumidos por esses indivíduos no âmbito da cultura digital, bem como os riscos e oportunidades implicados em cada um deles. Além disso, o livro possui uma composição rizomática: seus capítulos não seguem a uma lógica linear e hierarquizada, permitindo que cada um deles possa ser tomado isoladamente e em seguida fazer articulações com os demais, oportunidade esta permitida pelo alto grau 
de afinidade existente entre os assuntos tratados, assim como pela polissemia das situações descritas.

No tópico de introdução, os autores promovem uma breve contextualização do atual cenário mundial, apontando algumas transformações de ordem técnica, em sua maioria, incitadas pela intensificação da atividade científica, e econômica, ligadas aos processos de expansão e globalização dos mercados, ocorridas ao longo das últimas décadas. Em seguida, destacam o impacto que tais reordenamentos causaram no âmbito da cultura, ao produzir novos comportamentos, valores e práticas, decorrentes da popularização e generalização das novas tecnologias de informação e comunicação. É desse cenário que ascende o já aludido fenômeno dos nativos digitais, que vem causando espanto e preocupação por conta de seu envolvimento ambíguo com as tecnologias digitais.

No primeiro capítulo, Identidade, Palfrey e Gasser discorrem sobre como as identidades sociais desses indivíduos, no âmbito do ciberespaço, estão sujeitas a uma série de novos modos de sociabilidade, dentre os quais, destaca-se a internet. Com o aumento de sua presença neste domínio, os nativos digitais detêm cada vez menos controle sobre o tipo de informação associada à sua imagem diante dos demais membros de sua comunidade, uma vez que a visibilidade de suas ações se amplia, ao torná-lo ubíquo e acessível a qualquer um de seus contatos no Facebook, por exemplo. A isso, somam-se as questões abordadas no capítulo dois, (Dossiês), três, (Privacidade), quatro (Segurança) e nove (Agressores), que, respectivamente, discutem sobre a produção e armazenamento crescentes (e involuntário) dos "rastros" deixados pelos nativos digitais na rede; a dificuldade de reconhecer e definir as fronteiras entre as dimensões pessoal e pública da vida; a possibilidade de apropriação indevida dessas informações por parte de pessoas mal intencionadas; e o uso delas com a finalidade de prejudicar alguém - por exemplo, como ocorre nos atos de (cyber)bullying.

Em outro viés, o livro apresenta um conjunto de reflexões mais "inspiradoras", como aquelas feitas no capítulo cinco, criadores, em que o uso feito das tecnologias pelos nativos digitais é tomado como algo que vem a empoderar a imaginação desses jovens, constituindo-se como uma nova via de expressão e produção cultural a seu serviço. Nesse 
sentido, pode-se dizer que essa tônica se alinha às discussões dos capítulos 10 (inovadores), no qual certas ações dos nativos digitais são observadas sob o prisma do empreendedorismo; 11 (aprendizes), que se direciona aos novos esquemas cognitivos desenvolvidos por conta do contato precoce com as mídias; e 12 (ativistas), em que é esboçado o capacidade que os nativos digitais começam a adquirir no terreno cívico e da luta por e em causas coletivamente significativas.

Frente aos dilemas gerados pela problemática dos nativos digitais, Palfrey e Gasser tentam se esquivar da retórica do medo, evitando amparar suas proposições numa leitura alarmista e tecnofóbica. A postura dos autores é a de encarar os atuais modos de vida de jovens e crianças como algo que exige "bom senso", ao invés da adoção de medidas protecionistas e proibitivas que, com frequência, baseiam-se muito mais em impulsos saudosistas do que numa compreensão aprofundada e sistemática dos estilos de vida desses jovens e crianças.

Ao longo de toda a obra, os autores se mostram muito cautelosos em relação às polêmicas e impasses em torno dos nativos digitais, adotando a estratégia de abordar o fenômeno num quadro de ambivalência. Em outras palavras, Palfrey e Gasser, sob o ponto de vista discursivo e ideológico, não se propuseram a exaltar, tampouco a demonizar, os comportamentos desses jovens, mantendo sempre a tensão necessária de preservar o distanciamento crítico que a questão exige, distanciando-se de famigerados maniqueísmos que permeiam essa arena.

Em linhas gerais, Nascidos na Era Digital parece trazer importantes contribuições para diversas áreas do conhecimento, sobretudo para o campo educacional. Conforme os próprios autores esclarecem, as relações dos nativos digitais com suas instituições de referência vêm se alterando de modo significativo, em boa medida, em decorrência da acelerada expansão dos horizontes culturais que em outrora restringiam esses jovens a determinados modos de sociabilidade, nos quais, a família, a escola e o estado possuíam um status diferente daquele que vem se desenhando nas últimas décadas.

Evidentemente, essas transformações têm colocado em xeque muitos dos papéis sociais cumpridos historicamente por essas instituições, especialmente no tocante à 
preparação das novas gerações para o exercício de uma participação efetiva na esfera pública. Esse cenário sugere o caráter estratégico da revisão e reinterpretação de objetivos e estratégias, à luz dos novos desafios políticos, pedagógicos e culturais impostos pela consolidação cultura digital, de modo que o clássico projeto de formação humana voltado ao fortalecimento da autonomia dos sujeito não se desvaneça em meios a modismos e efemeridades típicos à contemporaneidade.

Para isso, é fundamental que pais, professores e gestores - ou policy makers, conforme Palfrey e Gasser -, submetam os relatos e sínteses presentes no livro a um minucioso processo de relativização. Afinal, como bem adverte Buckingham (2007; 2008), no contato com neologismos ${ }^{1}$ aplicados à juventude on-line, há sempre o risco de abordagens essencialistas: quando o conceito e as pesquisas sob o toldo da noção assumem o caráter de um quadro explicativo definitivo e universal, com prescrições que abrangem todas as atitudes, comportamentos e, principalmente, limitações desse segmento. Em última análise, trata-se de reconhecer a pluralidade de experiências e implicadas nos modos de ser criança e jovem atualmente, fato que impele a primazia das culturas locais no processo de definição dos perfis dos nativos digitais característicos a cada região, bem como nos esforços de implementação das ações afirmativas para lidar com esse grupo, seja no âmbito das políticas públicas, seja no reduto das famílias e das escolas.

\section{Referências}

BUCKINGHAM, David. Crescer na era das mídias eletrônicas. São Paulo: Edições Loyola, 2007.

BUCKINGHAM, David. Introducing Identity. In: BUCKINGHAM, D. (Org.).Youth, Identity, and Digital Media. Cambridge, MA: The MIT Press, p. 1-24, 2008.

PALFREY, John; GASSER, Urs. Nascidos na era digital: entendendo a primeira geração de nativos digitais. Porto Alegre: Artmed, 2011, 352 p.

\footnotetext{
${ }^{1}$ A título de exemplo, cito dois neologismos bastante difundidos nesse debate: "Geração Y", cunhada por Don Tapscott; e “Homo Zappiens”, de autoria de Wim Veen e Bem Vrakking.
} 
PRENSKY, Marc. Digital natives, digital immigrants. Lincoln: MCB University Press, On The Horizon, Vol. 9 No. 6, outubro, 2001.

Universidade do Estado de Santa Catarina - UDESC Programa de Pós-Graduação em Educação - PPGE 